\title{
Chrysin overcomes TRAIL resistance of cancer cells through Mcl-1 downregulation by inhibiting STAT3 phosphorylation
}

\author{
KRIENGSAK LIRDPRAPAMONGKOL ${ }^{1}$, HIROAKI SAKURAI ${ }^{3,4}$, SHERIF ABDELHAMED ${ }^{3}$, \\ SATORU YOKOYAMA ${ }^{3}$, SIRIVAN ATHIKOMKULCHAI ${ }^{6}$, AMORNRAT VIRIYAROJ $^{6}$, \\ SURESH AWALE ${ }^{5}$, SOMSAK RUCHIRAWAT ${ }^{2,7,8}$, IISNUSON SVASTI $^{1}$ and IKUO SAIKI ${ }^{3}$
}

\begin{abstract}
Laboratories of ${ }^{1}$ Biochemistry and ${ }^{2}$ Medicinal Chemistry, Chulabhorn Research Institute, Bangkok 10210, Thailand; ${ }^{3}$ Division of Pathogenic Biochemistry, Institute of Natural Medicine, ${ }^{4}$ Department of Cancer Cell Biology, Graduate School of Medicine and Pharmaceutical Sciences, ${ }^{5}$ Frontier Research Core for Life Sciences, University of Toyama, Toyama 930-0194, Japan; ${ }^{6}$ Faculty of Pharmacy, Srinakharinwirot University, Nakhon Nayok 26120; ${ }^{7}$ Program in Chemical Biology, Chulabhorn Graduate Institute, Bangkok 10210; ${ }^{8}$ Center of Excellence on Environmental Health and Toxicology (EHT), Commission on Higher Education (CHE), Ministry of Education, Bangkok 10400, Thailand
\end{abstract}

Received December 11, 2012; Accepted March 4, 2013

DOI: 10.3892/ijo.2013.1926

\begin{abstract}
Tumor necrosis factor-related apoptosis-inducing ligand (TRAIL) selectively kills various types of cancer cells without harming normal cells, but TRAIL resistance has been frequently observed in cancer cells. Propolis (bee glue) is a material collected from various plants by honeybees and is a rich source of bioactive compounds, including the natural flavonoid chrysin, which possesses multiple anticancer effects. We investigated the mechanism underlying the TRAIL sensitization effect of chrysin, which is a major constituent of Thai propolis, in human lung and cervical cancer cell lines. Propolis extract and chrysin sensitizes A549 and HeLa human cancer cell lines to TRAIL-induced apoptosis. The TRAIL sensitization effect of chrysin is not mediated by inhibition of TRAIL-induced NF- $\kappa$ B activation or by glutathione depletion. Immunoblot analysis using a panel of anti-apoptotic proteins revealed that chrysin selectively decreases the levels of Mcl-1 protein, by downregulating Mcl-1 gene expression as determined by qRT-PCR. The contribution of Mcl-1 in TRAIL resistance was confirmed by si-Mcl-1 knockdown. Among signaling pathways that regulate Mcl-1 gene expression, only constitutive STAT3 phosphorylation was suppressed by chrysin. The proposed action of chrysin in TRAIL sensitization by inhibiting STAT3 and downregulating Mcl-1 was supported by using a STAT3-specific inhibitor, cucurbitacin-I, which decreased Mcl-1 levels and enhanced
\end{abstract}

Correspondence to: Dr Kriengsak Lirdprapamongkol, Laboratory of Biochemistry, Chulabhorn Research Institute, 54 Kamphaeng Phet 6, Laksi, Bangkok 10210, Thailand

E-mail:kriengsak@cri.or.th

Key words: tumor necrosis factor-related apoptosis-inducing ligand, STAT3, apoptosis, propolis, natural products
TRAIL-induced cell death, similar to that observed with chrysin treatment. In conclusion, we show the potential of chrysin in overcoming TRAIL resistance of cancer cells and elucidate its mechanism of action.

\section{Introduction}

Tumor necrosis factor-related apoptosis-inducing ligand (TRAIL) is a transmembrane protein expressed on surface of several types of immune cells $(1,2)$. TRAIL is a member of tumor necrosis factor (TNF) family, and has recently received much attention because it selectively induces apoptosis in various cancer types without toxic effect to normal cells, independently of growth rate and p53 status of the cancer cells (2). TRAIL triggers apoptosis upon binding to its death receptors, DR4/TRAIL-R1 or DR5/TRAIL-R2, leading to activation of caspase- 8 which further activates caspase-3. In some cell types, TRAIL-induced apoptosis requires contribution of the mitochondrial pathway activated by caspase-8-mediated Bid cleavage (1). Clinical trials, using recombinant soluble TRAIL or agonistic monoclonal antibodies $(\mathrm{mAb})$ targeting TRAIL receptors, are being investigated for cancer therapy, either as monotherapy or in combination with other drugs (3). The appearance of TRAIL resistance has been observed in many cancer cell lines and primary tumor cells, and may be due to defects in TRAIL receptor signaling or dysregulation of anti-apoptotic proteins controlled by survival signaling pathways which are occasionally over-activated in cancer (4). Currently, there is much interest in searching for natural products that overcome TRAIL resistance for use during TRAIL treatment (5).

Propolis (bee glue) is a resinous material collected from various plants by honeybees for use as a defense against pathogenic microorganisms, and is attractive for pharmacological research as a rich source of bioactive compounds (6). Propolis extract has been shown to enhance TRAIL-induced apoptosis (7). However, the bioactivity and chemical composi- 
tion of propolis varies with geographic location $(6,8,9)$. Chrysin (5,7-dihydroxyflavone) is a flavonoid found in some propolis extracts and in plants (10). There is increasing evidence of potential benefits of chrysin as a pharmacological agent. Diverse anticancer effects and mechanisms have been reported for chrysin, including inducing apoptosis by Akt inhibition (11), inducing cell cycle arrest through p38-MAPK activation (12), and enhancing cytotoxicity of chemotherapeutic drugs via cellular glutathione depletion $(13,14)$. Chrysin was shown to sensitize HCT-116 human colorectal cancer cells to TNF $\alpha$ induced apoptosis, by inhibiting $\mathrm{TNF} \alpha$-induced NF- $\mathrm{KB}$ activation and preventing expression of FLIP $_{\mathrm{L}}$ anti-apoptotic protein which is an NF- $\mathrm{kB}$ target gene (15). Chrysin appears to enhance TRAIL-induced apoptosis in variety of human cancer cell lines originating from different organs including colorectal cancer, cervical cancer, hepatocellular carcinoma and nasopharyngeal carcinoma, suggesting that chrysin may have potential as a TRAIL sensitizer (16). However, until now, the mechanism for TRAIL sensitization effect of chrysin is still not known.

The mechanism of a TRAIL sensitizing agent should be clear before further study on using it in combination treatment with TRAIL or agonistic mAb targeting TRAIL receptors in clinical trials. Therefore, this study investigated the mechanism underlying the TRAIL sensitization effect of chrysin in TRAIL resistant human cancer cell lines, by determining the involvement of NF- $\mathrm{KB}$ activation, glutathione depletion, and levels of anti-apoptotic proteins in TRAIL sensitization, and further exploring the contributing signaling pathways.

\section{Materials and methods}

Propolis extraction and isolation of compounds. Propolis was collected from a hive of Apis mellifera from Chiangmai province, Thailand, in August 2006. A voucher specimen (SWU 0212) was deposited at the Faculty of Pharmacy, Srinakharinwirot University, Nakhon Nayok province, Thailand. Thai propolis $(1 \mathrm{~kg})$ was extracted by sonication with methanol (2 liters, $90 \mathrm{~min} \times 3$ ) at room temperature. Removal of methanol yielded the methanol extract $(517 \mathrm{~g})$. Part of the methanol extract $(140 \mathrm{~g})$ was subjected to silica gel column chromatography using dichloromethane, with increasing concentration of methanol, give 16 fractions. Chrysin (732 mg) and tectochrysin $(314 \mathrm{mg})$ were isolated by crystallization from fractions. Chrysin and tectochrysin were identified by comparison of physical and spectroscopic data with authentic standard and literature values $(17,18)$.

Reagents and antibodies. Recombinant human TRAIL and recombinant human tumor necrosis factor (TNF)- $\alpha$ were purchased from Peprotech (London, UK). Curcumin was obtained from Fluka Chemika (Steinheim, Switzerland). $\mathrm{N}$-acetylcysteine (NAC) and 3-(4,5-dimethythiazol-2-yl)-2,5-diphenyltetrazolium bromide (MTT), and chrysin were purchased from Sigma-Aldrich (St. Louis, MO). STAT3 specific inhibitor (cucurbitacin-I) and IKK-2 inhibitor IV were obtained from Calbiochem (San Diego, CA). Lipofectamine 2000 reagent and hygromycin B were purchased from Invitrogen (Carlsbad, CA). Test compounds were dissolved in dimethyl sulfoxide (DMSO) and kept as a stock solution at $-20^{\circ} \mathrm{C}$. The final concentration of DMSO was kept below $0.2 \%$ throughout the study. Primary antibodies specific to caspase-3, poly (ADP-ribose) polymerase (PARP), Mcl-1, Bcl-XL, XIAP, survivin, FLIP, STAT3 and phosphorylated form of STAT3 $\left(\mathrm{Tyr}^{705}\right)$, Akt $\left(\mathrm{Ser}^{473}\right)$, ERK1/2 $\left(\mathrm{Thr}^{202} / \mathrm{Tyr}^{204}\right), \mathrm{p} 38\left(\mathrm{Thr}^{180} / \mathrm{Tyr}^{182}\right)$, JNK $\left(\mathrm{Thr}^{183} / \mathrm{Tyr}^{185}\right), \mathrm{p} 65$ NF- $\kappa B\left(\mathrm{Ser}^{536}\right)$ were obtained from Cell Signaling Technology (Beverly, MA). Primary antibodies specific to actin, pan 14-3-3, Akt, ERK1/2, p38, JNK and p65 NF- $\kappa$ B were obtained from Santa Cruz Biotechnology (Santa Cruz, CA).

Cell culture. A549 human lung adenocarcinoma and HeLa human cervical carcinoma are TRAIL resistant cell lines (19). Cell lines were obtained from the American Type Culture Collection (ATCC, Rockville, MD). A549 was cultured in RPMI-1640 supplemented with $10 \%$ fetal bovine serum (FBS), $100 \mathrm{U} / \mathrm{ml}$ of penicillin and $100 \mu \mathrm{g} / \mathrm{ml}$ of streptomycin. HeLa was cultured in DMEM supplemented with $2 \mathrm{mM} \mathrm{L}$-glutamine, $10 \% \mathrm{FBS}$ and the antibiotics. The cells were maintained at $37^{\circ} \mathrm{C}$ in a humidified atmosphere of $5 \% \mathrm{CO}_{2}$.

Cell viability assay. Cell viability after treatment was determined by MTT method (20). Briefly, cells in 96-well plates (100 $\mu 1 /$ well) were pretreated by adding medium $(100 \mu \mathrm{l})$ containing test compound to the wells, and incubated for $30 \mathrm{~min}$, then aliquots of TRAIL in medium $(5 \mu \mathrm{l})$ were added to each well (final concentration of $100 \mathrm{ng} / \mathrm{ml}$ for A549 cells, or $200 \mathrm{ng} / \mathrm{ml}$ for HeLa cells), and further incubated for $24 \mathrm{~h}$. Then, the wells were replaced and incubated with fresh culture media containing MTT $(0.5 \mathrm{mg} / \mathrm{ml})$ for $2 \mathrm{~h}$ at $37^{\circ} \mathrm{C}$. Finally, the media were removed and DMSO $(100 \mu \mathrm{l})$ was added to the wells, and absorbance was measured at $550 \mathrm{~nm}$ in a microplate reader, subtracted with absorbance at $650 \mathrm{~nm}$. The number of viable cells was determined from the absorbance. Assays were performed in triplicate wells. Data were expressed as percent viability compared with control.

Establishment of stable $N F-\kappa B$ reporter cell line. A549 cells were transfected with pGL4.32[luc2P/NF-кB-RE/Hygro] vector (Promega, Madison, WI) using Lipofectamine 2000 reagent according to manufacturer's protocol. After transfection for $24 \mathrm{~h}$, the transfected cells were selected by sub-culturing into new flasks containing RPMI-1640 supplemented with 10\% FBS and $800 \mu \mathrm{g} / \mathrm{ml}$ hygromycin B and maintained in this media over 2 weeks to obtain the stable transfected cells (A549/NF- $\mathrm{kB}$ ).

$N F-\kappa B$ transcriptional activity assay. NF- $\kappa \mathrm{B}$ transcriptional activity was determined by luciferase reporter gene assay.

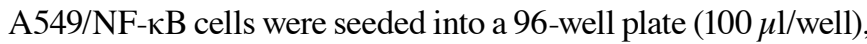
and left overnight. Cells were pretreated with test compound (100 $\mu$ l) for $30 \mathrm{~min}$, followed by adding $5 \mu \mathrm{l}$ of medium containing TNF $\alpha$ or TRAIL, and further incubated for $3 \mathrm{~h}$. Cells were then lysed with $25 \mu \mathrm{l}$ of passive lysis buffer (Promega), and $20 \mu \mathrm{l}$ of cell lysate was mixed with $50 \mu \mathrm{l}$ of luciferase assay reagent (Promega). Luminescence was determined using a luminometer (Atto, Tokyo, Japan).

Immunoblot analysis. Immunoblot analysis was performed as previously described (21). Briefly, whole cell lysates were subjected to electrophoresis in 7.5 or $10 \%$ SDS-PAGE, and electrophoretically transferred to Immobilon-P nylon membrane (Millipore, Bedford, MA). The membranes were blocked with BlockAce (Dainippon Pharmaceutical, Co. Ltd., Osaka, Japan) 
for at least $2 \mathrm{~h}$, and probed with the indicated primary antibodies overnight, followed by horseradish peroxidase-conjugated secondary antibodies (Dako, Glostrup, Denmark). Bands were visualized using ECL reagents (Amersham Bioscience, Piscataway, NJ).

Quantitative reverse transcriptase-polymerase chain reaction ( $q R T-P C R)$. Isolation of total cellular RNA from cells was performed using RNeasy mini kit (Qiagen, Valencia, CA), and $2 \mu \mathrm{g}$ of the total cellular RNA was used to synthesize first-strand cDNA by using SuperScript III Reverse Transcriptase Kit (Invitrogen). Quantitative determination of gene expression was performed by real-time PCR on a LightCycler ${ }^{\circledR} 2.0$ Instrument (Roche). PCR primer sequences were obtained from following references; human Mcl-1 (22); human $\beta$-actin (23). Mcl-1 primer (fwd) 5'-CGG TAA TCG GAC TCA ACC TC-3'; and Mcl-1 primer (rev) 5'-CCT CCT TCT CCG TAG CCA A-3'. $\beta$-actin primer (fwd) 5'-GAC CTG ACT GAC TAC CTC ATG A-3'; and $\beta$-actin primer (rev) 5'-AGC ATT TGC GGT GGA CGA TGG AG-3'. The PCR reaction mixture $(20 \mu \mathrm{l})$ was composed of $1 \mu \mathrm{l}$ of 5-fold diluted cDNA solution, $10 \mu \mathrm{l}$ QuantiTect ${ }^{\mathrm{TM}}$ SYBR-Green PCR Master mix (Qiagen), PCR primers and sterile distilled water. An initial activation step at $95^{\circ} \mathrm{C}$ for 15 min was followed by 40 cycles comprising denaturation at $94^{\circ} \mathrm{C} / 15 \mathrm{sec}$, annealing at $55^{\circ} \mathrm{C} / 30 \mathrm{sec}$, and extension at $72^{\circ} \mathrm{C} / 30 \mathrm{sec}$. Expression level of $\mathrm{Mcl}-1$ gene was normalized to $\beta$-actin gene, and calculated from crossing point $\left(\mathrm{C}_{\mathrm{p}}\right)$ value of the sample, relative gene expression level $=2^{\text {(Cp actin }-\mathrm{Cp} \text { target })}$. The relative change in gene expression compared with untreated conditions was expressed as fold change, calculated by $2^{-\Delta \Delta \mathrm{Cp}}$ method (24).

Transfection of small interfering RNAs. Silencing of Mcl-1 expression in A549 cells was performed as previously described (19). Human Mcl-1 Stealth RNAi ${ }^{\mathrm{TM}}$ siRNA (HSS181042) was purchased from Invitrogen. Firefly luciferase (GL2) siRNA was obtained from Hokkaido System Science Co. Ltd. (Sapporo, Japan), and used as control siRNA (19). A549 cells were transfected with siRNAs at a final concentration of $20 \mathrm{nM}$, using Lipofectamine 2000 reagent. Cells were treated with TRAIL at $24 \mathrm{~h}$ after transfection.

Statistical analysis. Data are expressed as mean + SD, and analyzed by Student's two-tailed t-test to determine the significance of differences between groups. A p-value of lower than 0.05 was considered to be significant.

\section{Results}

Enhancement of TRAIL-induced apoptosis in human cancer cells by Thai propolis extract and chrysin. Initially, TRAIL sensitization effect of Thai propolis extract was examined in a TRAIL resistant cell line, A549. Pretreatment with propolis extract $(25-100 \mu \mathrm{g} / \mathrm{ml})$ for $30 \mathrm{~min}$, followed by TRAIL stimulation for $24 \mathrm{~h}$, enhanced TRAIL-induced cell death. At the highest propolis concentration test $(100 \mu \mathrm{g} / \mathrm{ml})$, cell viability of the combination treatment was 38\%, compared with 63 and $98 \%$ viability with propolis alone and TRAIL alone, respectively (Fig. 1A). Chrysin and tectochrysin were found to be two major constituents of the Thai propolis extract. Chrysin enhanced TRAIL-induced cell death, with cell viability being $47 \%$ in the combination treatment, compared to 86 and $92 \%$ viability with chrysin alone and TRAIL alone, respectively, while tectochryin did not show significant effect (Fig. 1B). TRAIL sensitization effect of chrysin was observed in a dose-dependent manner over the tested ranges $(20-60 \mu \mathrm{M})$ in both A549 and HeLa cell lines, which originated from different organs (Fig. 1C).

Hallmarks of cells undergoing apoptosis are cleavage of procaspase-3 and poly(ADP-ribose) polymerase (PARP). Massive cell death of A549 and HeLa cells could be observed as early as $3 \mathrm{~h}$ after treatment with chrysin/TRAIL combination (Fig. 1D), concordant with enhancement of apoptosis as clearly shown by increased cleavage of pro-caspase-3 and PARP (Fig. 1E). Our results revealed that apoptosis-inducing effect of TRAIL was enhanced by chrysin.

TRAIL sensitization effect of chrysin is not mediated by $N F-\kappa B$ inhibition. In addition to inducing apoptosis signaling, TRAIL and TNF $\alpha$ receptors also activate survival signaling such NF- $\kappa$ B which regulates expression of several anti-apoptotic proteins to counteract the apoptosis signaling (1). Since chrysin was shown to sensitize TNFa-induced apoptosis in human cancer cells by inhibiting NF- $\kappa \mathrm{B}$ activation (15), thus, we examined effect of chrysin on TNF $\alpha$ - or TRAIL-induced NF- $\kappa \mathrm{B}$ activation in A549/NF- $\kappa$ B stable cell line. Stimulation of TNF $\alpha$ for $3 \mathrm{~h}$ induced activation and increased transcriptional activity of NF- $\kappa \mathrm{B}$ by 20.8-fold compared to control (Fig. 2A). TNF $\alpha$-induced NF- $\kappa \mathrm{B}$ activation was diminished by chrysin pretreatment $(60 \mu \mathrm{M})$, with $79 \%$ inhibition observed, while IKK-2 inhibitor pretreatment $(10 \mu \mathrm{M})$ led complete inhibition (Fig. 2A). In contrast, TRAIL stimulation slightly induced $N F-\kappa B$ activation by 1.1-fold, while NF- $\kappa \mathrm{B}$ activation was more increased by chrysin alone or chrysin/TRAIL combination treatment, with 1.8- and 1.9-fold induction respectively (Fig. 2A). These results indicated that chrysin did not inhibit TRAIL-induced NF- $\kappa$ B activation in A549 cells. Furthermore, inhibition of TRAIL-induced NF- $\kappa$ B activation by IKK-2 inhibitor did not significantly enhance cell death in A549 cells (Fig. 2B), indicating that inhibition of $\mathrm{NF}-\kappa \mathrm{B}$ activation is unlikely to be the mechanism of chrysin for TRAIL sensitization.

Glutathione depletion does not contribute to TRAIL sensitization effect of chrysin. Chrysin has been shown to sensitize A549 cells to chemotherapeutic drugs by depleting intracellular glutathione $(13,14)$. N-acetylcysteine (NAC), a precursor of glutathione synthesis, has been shown to reverse TRAIL sensitization by curcumin (25). We evaluated the involvement of glutathione depletion in TRAIL sensitization effect of chrysin by pretreatment of A549 cells with NAC (10 mM) for $2 \mathrm{~h}$, to increase intracellular glutathione level before exposure to TRAIL combination treatment. If the cytotoxic effect of the combination treatment is mediated by glutathione depletion effect, the NAC pretreatment will abolish the cytotoxic effect. The results showed that TRAIL sensitization effect of chrysin was unaffected by NAC pretreatment, but TRAIL sensitization effect of curcumin was potently reversed by NAC pretreatment (Fig. 3). The results clearly indicated that glutathione depletion does not contribute to the TRAIL sensitization effect of chrysin.

Mcl-1 downregulation mediates TRAIL sensitization effect of chrysin. Many naturally occurring polyphenols enhance 

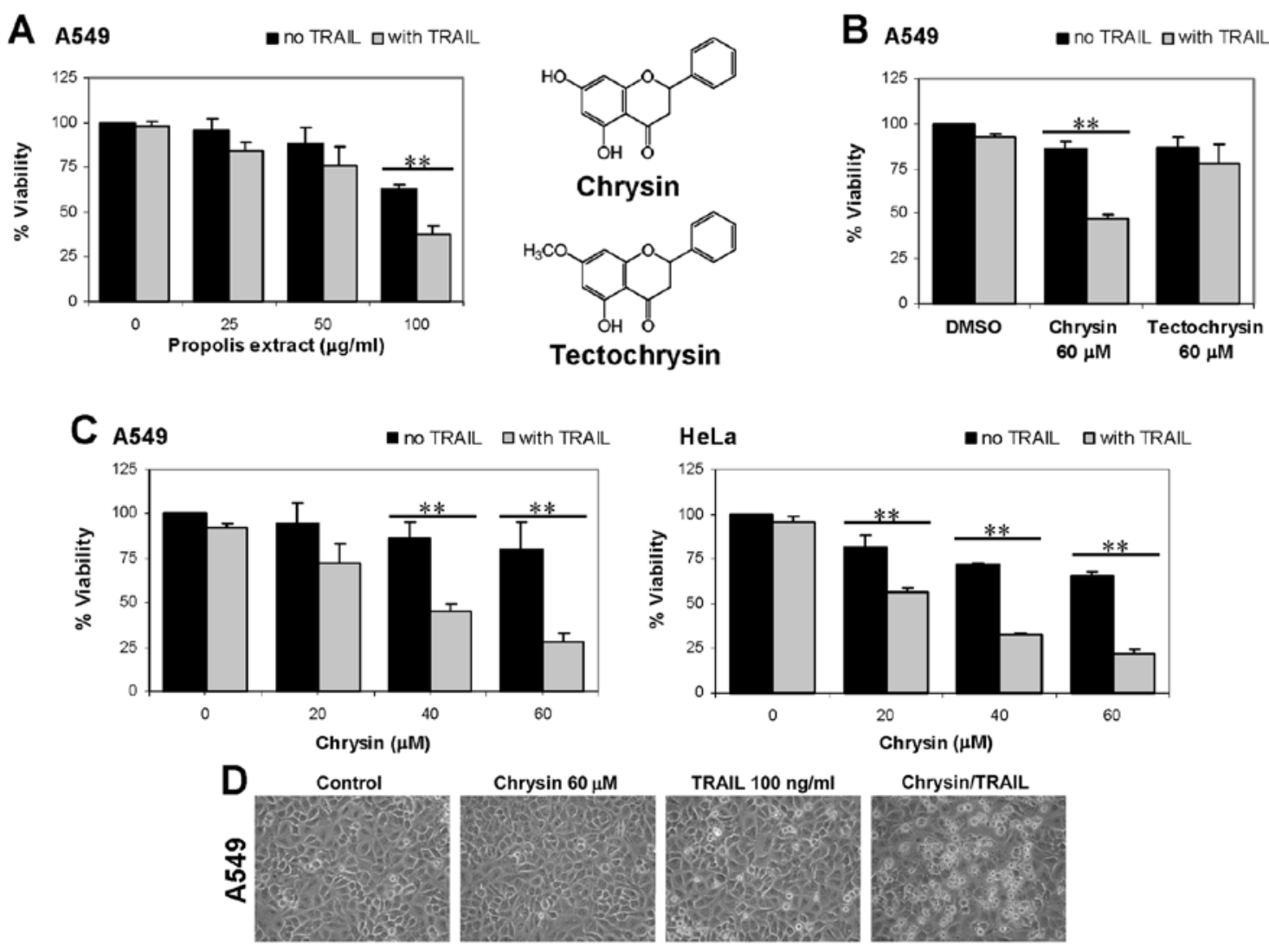

Chrysin/TRAIL

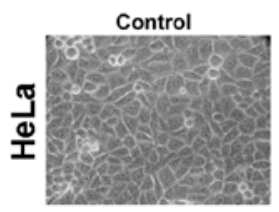

Chrysin $60 \mu \mathrm{M}$
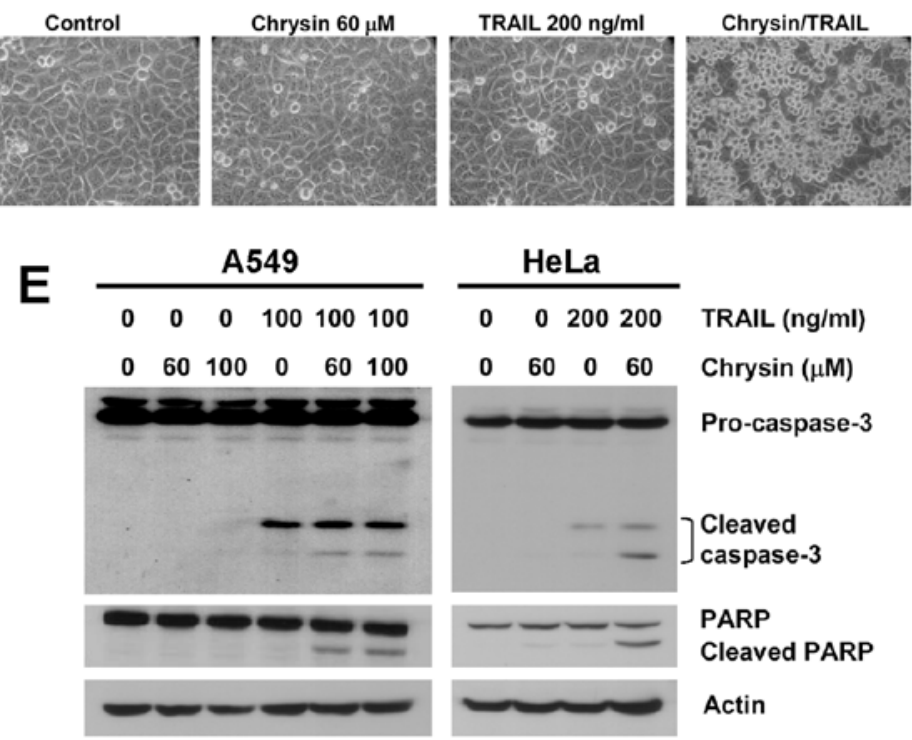

Figure 1. TRAIL sensitization effect of Thai propolis extract and chrysin. Enhancement of TRAIL-induced cell death by Thai propolis extract (A), and its major constitutents - chrysin and tectochrysin (B) in A549 cells. (C) Dose-dependent effect of chrysin on TRAIL sensitization in A549 and HeLa cells. The cells were pretreated with test compound for $30 \mathrm{~min}$, and further incubated with and without TRAIL ( $100 \mathrm{ng} / \mathrm{ml}$ for A549 cells or $200 \mathrm{ng} / \mathrm{ml}$ for HeLa cells) for $24 \mathrm{~h}$, after which cell viability was determined by MTT assay. Data are expressed as mean \pm SD from three independent experiments, and significant difference between with TRAIL and without TRAIL shown by ${ }^{* *} \mathrm{p}<0.01$. Apoptosis-inducing effect of TRAIL was enhanced by chrysin. Cells were pretreated with chrysin for 30 min, and further incubated in the presence or absence of TRAIL for $3 \mathrm{~h}$. (D) Photographs were taken at original magnification, x50. (E) Whole cell lysates were analyzed by immunoblotting for apoptotic proteins.

TRAIL sensitization through downregulation of anti-apoptotic proteins (26). We further examined effect of chrysin on levels of several anti-apoptotic proteins, including Mcl-1, Bcl-XL, XIAP, survivin and 14-3-3, in both A549 and HeLa cells. The results showed that, at $3 \mathrm{~h}$ after treatment, chrysin alone (60-100 $\mu \mathrm{M})$ or in combination with TRAIL selectively decreased Mcl-1 protein level, while the levels of other proteins remained unaffected (Fig. 4A). The dose-dependent decrease in Mcl-1 protein level by chrysin was observed in both A549 and HeLa cell lines (Fig. 4A and B). 
A

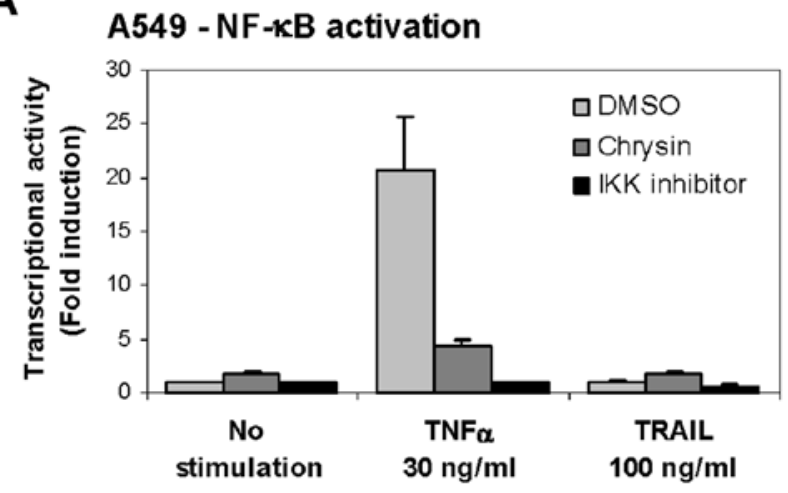

B

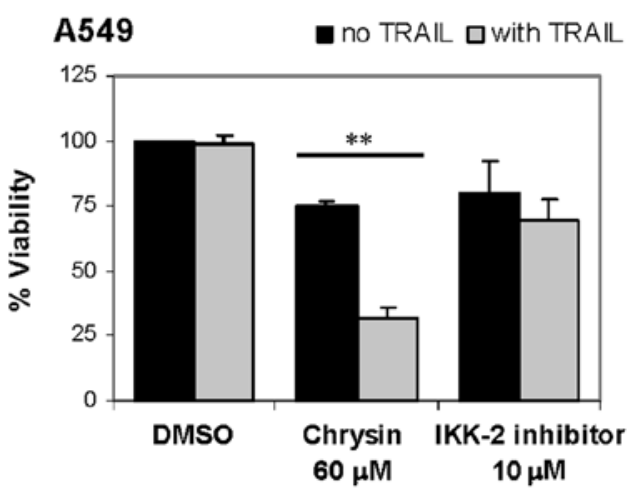

Figure 2. NF- $\kappa \mathrm{B}$ inhibition does not mediate the TRAIL sensitization effect of chrysin. (A) Effect of chrysin on NF- $\kappa$ B transcriptional activity. A549 cells stably transfected with NF- $\mathrm{BB}$ reporter plasmid were pretreated with chrysin $(60 \mu \mathrm{M})$ or IKK-2 inhibitor $(10 \mu \mathrm{M})$ for $30 \mathrm{~min}$, and further stimulated with TNF $\alpha(30 \mathrm{ng} / \mathrm{ml})$ or TRAIL $(100 \mathrm{ng} / \mathrm{ml})$ for $3 \mathrm{~h}$. NF- $\mathrm{KB}$ transcriptional activity was then determined by luciferase assay. (B) $\mathrm{NF}-\kappa \mathrm{B}$ inhibitor does not enhance TRAIL-induced cell death in A549. The cells were pretreated with test compound for $30 \mathrm{~min}$, and further incubated in the presence or absence of TRAIL (100 ng/ml) for $24 \mathrm{~h}$. Cell viability was determined by MTT assay, and significant difference between with TRAIL and without TRAIL is shown by ${ }^{* *} \mathrm{p}<0.01$.

Effect of chrysin on another short half-life anti-apoptotic protein, FLIP, was examined compared with Mcl-1. The rapid turnover rate of both proteins in cells is mediated by the proteasome (27). FLIP has 2 isoforms - FLIP Lnd $_{\text {FLIP }}$, but FLIP $_{\mathrm{S}}$ was not detected in our cell lines. Chrysin treatment $(60 \mu \mathrm{M})$ for $3 \mathrm{~h}$ decreased Mcl-1 level, while $\mathrm{FLIP}_{\mathrm{L}}$ levels in both cell lines were not reduced (Fig. 4C).

To explore the cause of Mcl-1 reduction by chrysin, we determined mRNA level of Mcl-1 gene after treatment by using qRT-PCR. Effect of chrysin on Mcl-1 gene expression was clearly demonstrated, chrysin $(60 \mu \mathrm{M})$ treatment for $3 \mathrm{~h}$ reduced Mcl-1 mRNA level by 52\% (Fig. 4D). The results suggested that modulation of TRAIL sensitivity of cancer cells by chrysin was occurred through downregulation of Mcl-1 gene expression.

Silencing Mcl-1 expression is sufficient to enhances TRAILinduced apoptosis. To confirm that reduction of Mcl-1 level was able to sensitize cells to TRAIL-induced apoptosis, siMcl-1 transfection was used to silence Mcl-1 expression in A549 cells,

\section{A549 - Effect of antioxidant pretreatment}

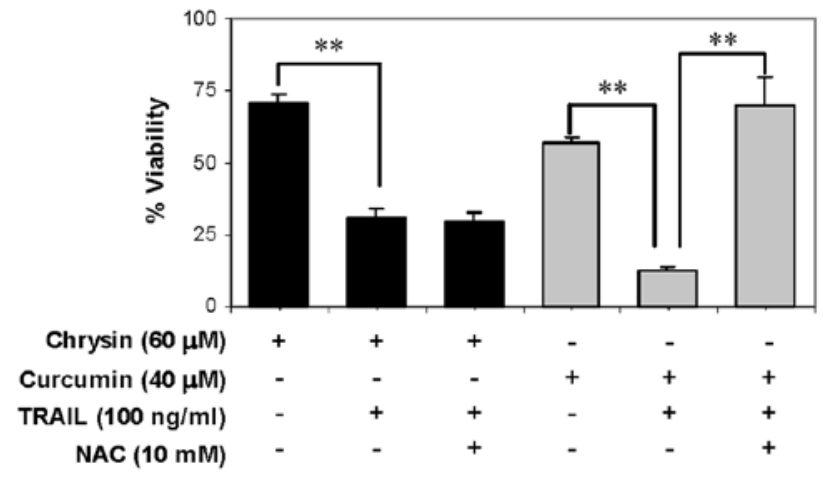

Figure 3. Effect of antioxidant pretreatment on TRAIL sensitization by chrysin. Cells were pretreated with NAC, glutathione precursor $(10 \mathrm{mM})$ for $2 \mathrm{~h}$, then treated with chrysin or curcumin for $30 \mathrm{~min}$, and further incubated in the presence or absence of TRAIL for $24 \mathrm{~h}$. Cell viability was determined by MTT assay. Data are expressed as mean \pm SD from three independent experiments, and significant difference between groups are shown by ${ }^{* *} \mathrm{p}<0.01$.

while siLuc was used as control siRNA. At $24 \mathrm{~h}$ after transfection, the level of Mcl-1 protein was obviously decreased in siMcl-1 transfected cells compared with siLuc transfected cells (Fig. 5A). After TRAIL stimulation for $3 \mathrm{~h}$, many apoptotic cells were observed in the siMcl-1 transfected cells (Fig. 5B), correlating with cleavage of pro-caspase-3, while the procaspase-3 cleavage was faintly detected in TRAIL-stimulated siLuc transfected cells (Fig. 5A). Taken together, the results confirmed that TRAIL sensitization effect of chrysin was mediated by Mcl-1 downregulation. Thus, we further investigated mechanism of Mcl-1 modulation by chrysin.

Chrysin downregulates Mcl-1 expression through inhibiting STAT3 tyrosine phosphorylation. Mcl-1 gene expression is regulated by multiple signaling pathways, including STAT3, Akt and p38 pathways (28). We examined the effects of chrysin treatment (60-100 $\mu \mathrm{M}$ ) for $3 \mathrm{~h}$, either alone or in combination with TRAIL, on several survival signaling pathways including STAT3, Akt, ERK, p38 and $\mathrm{NF}-\kappa \mathrm{B}$. Among the selected pathways, marked inhibition was obtained only in constitutive STAT3 tyrosine phosphorylation $\left(\mathrm{Tyr}^{705}\right.$ ), in both A549 and HeLa cells (Fig. 6A). $\mathrm{Tyr}^{705}$ phosphorylation of STAT3 is necessary for DNA-binding and transcriptional activity of STAT3 (29). Correlation between decreased STAT3 tyrosine phosphorylation and Mcl-1 downregulation was observed in A549 cells treated with chrysin in a time-dependent manner, while Akt phosphorylation was not affected within the time-course measured (Fig. 6B). The results suggested that STAT3 was the target of chrysin for modulating level of Mcl-1 expression.

STAT3 specific inhibitor decreases Mcl-1 level and enhances TRAIL-induced cell death. To confirm that Mcl-1 expression is regulated by STAT3, A549 cells was treated with a specific inhibitor of STAT3 (cucurbitacin-I) for $3 \mathrm{~h}$, the result showed that the STAT3 inhibitor decreased both STAT3 tyrosine phosphorylation and Mcl-1 level (Fig. 7A). Furthermore, the STAT3 inhibitor enhanced TRAIL-induced cell death (Fig. 7B) in a dose-dependent manner, similar to that observed with chrysin treatment. Collectively, our results indicated that the TRAIL 
A

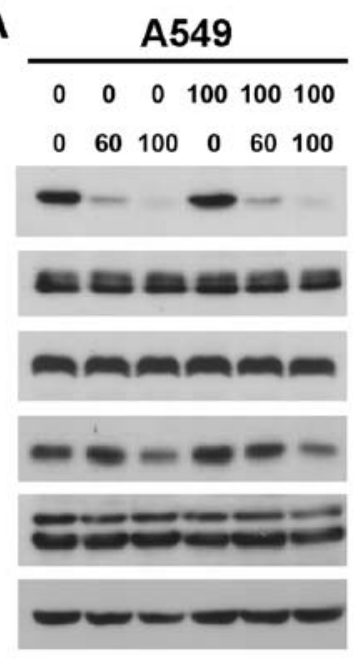

HeLa

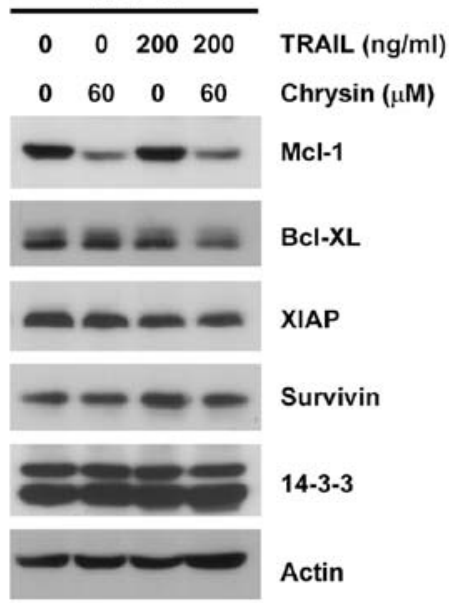

B

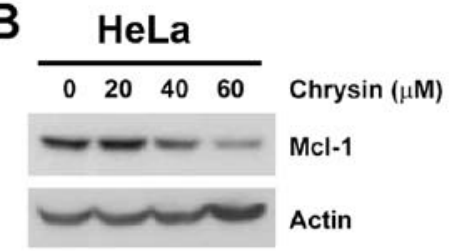

C

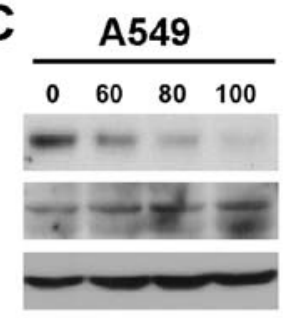

HeLa

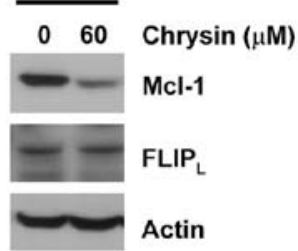

D

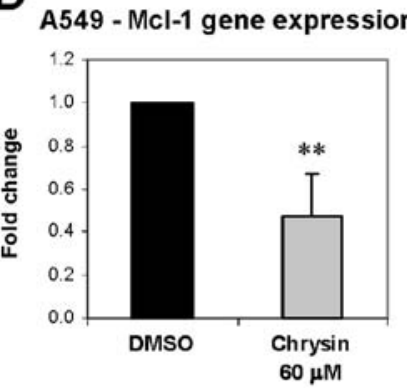

Figure 4. Effect of chrysin and TRAIL on levels of anti-apoptotic proteins. (A and B) A549 and HeLa were pretreated with chrysin for 30 min, and further incubated in the presence or absence of TRAIL for $3 \mathrm{~h}$. Whole cell lysates were analyzed by immunoblotting for anti-apoptotic proteins. (C) Chrysin dose-dependently decreases Mcl-1 protein level but does not affect FLIP $\mathrm{L}_{\mathrm{L}}$ level. A549 and HeLa were treated with chrysin for $3 \mathrm{~h}, \mathrm{Mcl}-1$ and FLIP $_{\mathrm{L}}$ protein were detected by immunoblot analysis. (D) Effect of chrysin on Mcl-1 gene expression. A549 cells were treated with chrysin for $3 \mathrm{~h}, \mathrm{Mcl}-1 \mathrm{mRNA}$ level was determined by qRT-PCR and normalized to $\beta$-actin. Change in gene expression compared with control is expressed as fold change. Data are expressed as mean \pm SD from three independent experiments, and significant difference from control is shown by ${ }^{* *} \mathrm{p}<0.01$.

A

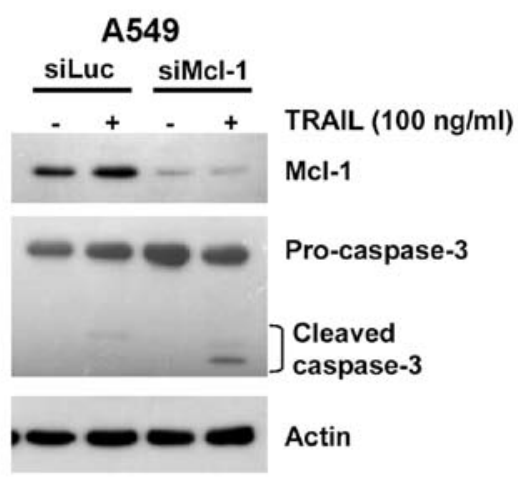

B

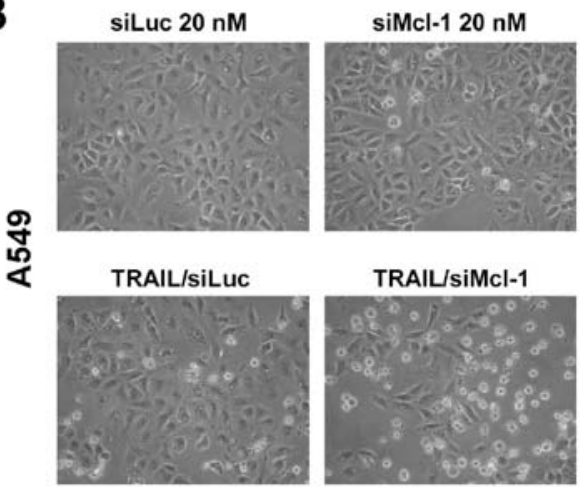

sensitization effect of chrysin was mediated by Mcl-1 downregulation through inhibition of constitutive STAT3 tyrosine phosphorylation.

\section{Discussion}

Induction of apoptosis via TRAIL receptor is a promising targeted therapy, but this strategy also faces a similar problem to the use of other chemotherapeutic drugs, because TRAIL resistance is found in variety of cancers. The TRAIL sensitization effect of chrysin was recently reported (16), but the underlying mechanism has not been elucidated until now. In the present study, we demonstrated a novel mechanism for apoptosis-sensitizing effect of chrysin that overcomes TRAIL resistance of cancer cells.

We demonstrated that downregulation of Mcl-1 anti-apoptotic protein by STAT3 inhibition is the mechanism for chrysin

Figure 5. Silencing Mcl-1 expression enhances TRAIL-induced apoptosis. At $24 \mathrm{~h}$ after transfection with siMcl-1 or siLuc (control), A549 cells were incubated in the presence or absence of TRAIL for $3 \mathrm{~h}$. (A) Whole cell lysates were analyzed by immunoblotting. (B) Photographs were taken at original magnification, $\mathrm{x} 50$. 
A

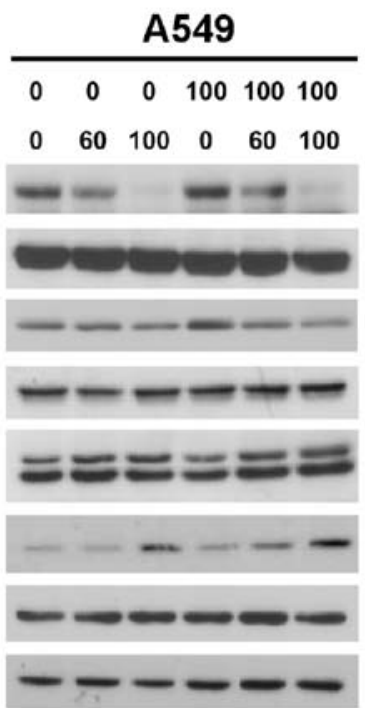

HeLa

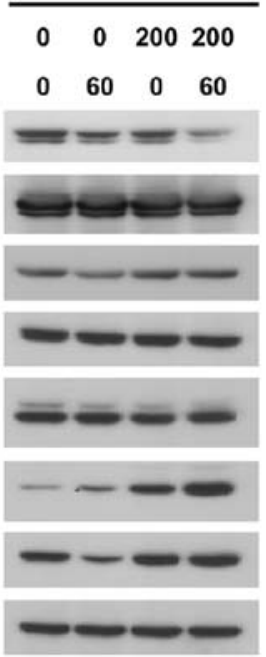

B

TRAIL (ng/ml)
Chrysin $(\mu \mathrm{M})$
P-STAT3 Tyr
STAT3
P-Akt
Akt
P-ERK
P-p38
P-p65 NF-kB
p65 NF-kB

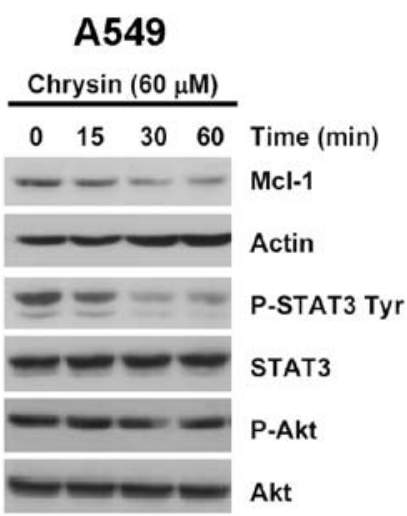

Figure 6. Effect of chrysin on signaling pathways that regulate Mcl-1 gene expression. (A) Effects of chrysin on multiple signaling pathways. A549 and HeLa were pretreated with chrysin for $30 \mathrm{~min}$, and further incubated in the presence or absence of TRAIL for $3 \mathrm{~h}$. Whole cell lysates were analyzed by immunoblot analysis. (B) Correlation of time-dependent decrease in STAT3 phosphorylation and Mcl-1 level by chrysin treatment. A549 cells were treated with chrysin for the indicated time, and whole cell lysates were analyzed by immunoblot analysis.

A
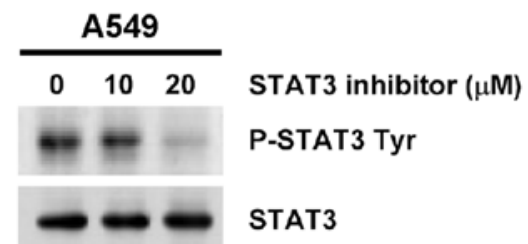

$\because-\ldots$ Mcl-1
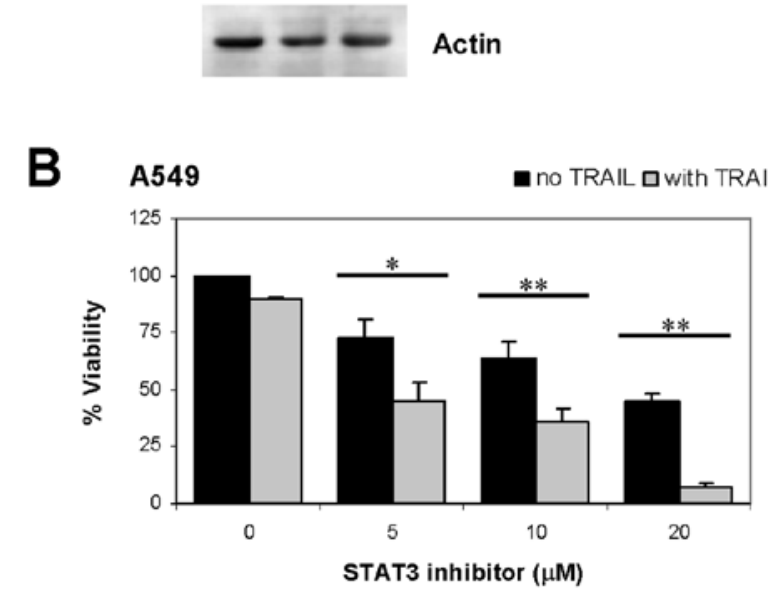

Figure 7. STAT3 specific inhibitor decreases Mcl-1 level and enhances TRAIL-induced cell death. (A) Decrease in Mcl-1 level by STAT3 inhibitor. A549 cells were treated with STAT3 inhibitor (cucurbitacin-I) for $3 \mathrm{~h}$, and whole cell lysates were analyzed by immunoblotting. (B) STAT3 inhibitor enhances TRAIL-induced cell death. A549 cells were pretreated with STAT3 inhibitor for $30 \mathrm{~min}$, and further incubated in the presence or absence of TRAIL (100 $\mathrm{ng} / \mathrm{ml})$ for $24 \mathrm{~h}$. Cell viability was determined by MTT assay. Data are expressed as mean \pm SD from three independent experiments, and significant difference between TRAIL and no TRAIL are shown by ${ }^{*} \mathrm{p}<0.05,{ }^{*} \mathrm{p}<0.01$.

in enhancing the apoptosis-inducing effect of TRAIL. Mcl-1 is a Bcl-2 family anti-apoptotic protein, contributing to TRAIL resistance by sequestering several proapoptotic proteins, such as Bak, Bim and Puma, preventing their function to release cytochrome $c$ from mitochondria during TRAIL stimulation (30). STAT3 regulates anti-apoptotic genes including Mcl-1, survivin and Bcl-XL (31). However, Mcl-1 differs from other anti-apoptotic proteins by having a very short intracellular half-life ( $40 \mathrm{~min})$ and rapid turnover rate (32). This could explain the rapid apoptosis induction by the chrysin/TRAIL combination, which could be observed as early as $3 \mathrm{~h}$ after treatment (Fig. 1E). While chrysin treatment decreased Mcl-1 level, the treatment did not change the level of FLIP $_{L}$, another short half-life anti-apoptotic protein (33), indicating the specific effect of chrysin. Results of silencing Mcl-1 expression by siRNA confirmed that the decreased Mcl-1 level by chrysin was sufficient to enhance apoptosis-inducing effect of TRAIL. The mechanism of reversal of TRAIL resistance by STAT3/Mcl-1 downregulation was not only found in our lung and cervical cancer cells, but was also observed in variety of cancer types including breast cancer, pancreatic cancer and hepatocellular carcinoma (34-36).

The reduction of Mcl-1 level by chrysin has been observed in other cancer cell types including anaplastic thyroid cancer and T-cell leukemia $(37,38)$. The report of Polier et al demonstrated that Mcl-1 downregulation by chrysin in T cell leukemia was a result of inhibiting a transcription regulator, cyclindependent kinase 9 (CDK9), and subsequent reduction in $\mathrm{Ser}^{2}$ phosphorylation of RNA polymerase II (RNA pol II), leading to decrease in Mcl-1 gene expression in T-cell leukemic cell line (37). The $\mathrm{Ser}^{2}$ phosphorylation in the carboxy-terminal domain of RNA pol II by CDK9 activity is required for the transcription elongation stage of mRNA synthesis (39). It has been reported that, during upregulation of STAT3 target genes, $\mathrm{Tyr}^{705}$-phosphorylated STAT3 directly associated with CDK9 in nucleus, and this complex recruited RNA pol II to promoter site of the target genes, increasing $\mathrm{Ser}^{2}$ phosphorylation of the RNA pol II, allowing transcriptional elongation of mRNA synthesis $(40,41)$. The implication of CDK9 and RNA pol II 


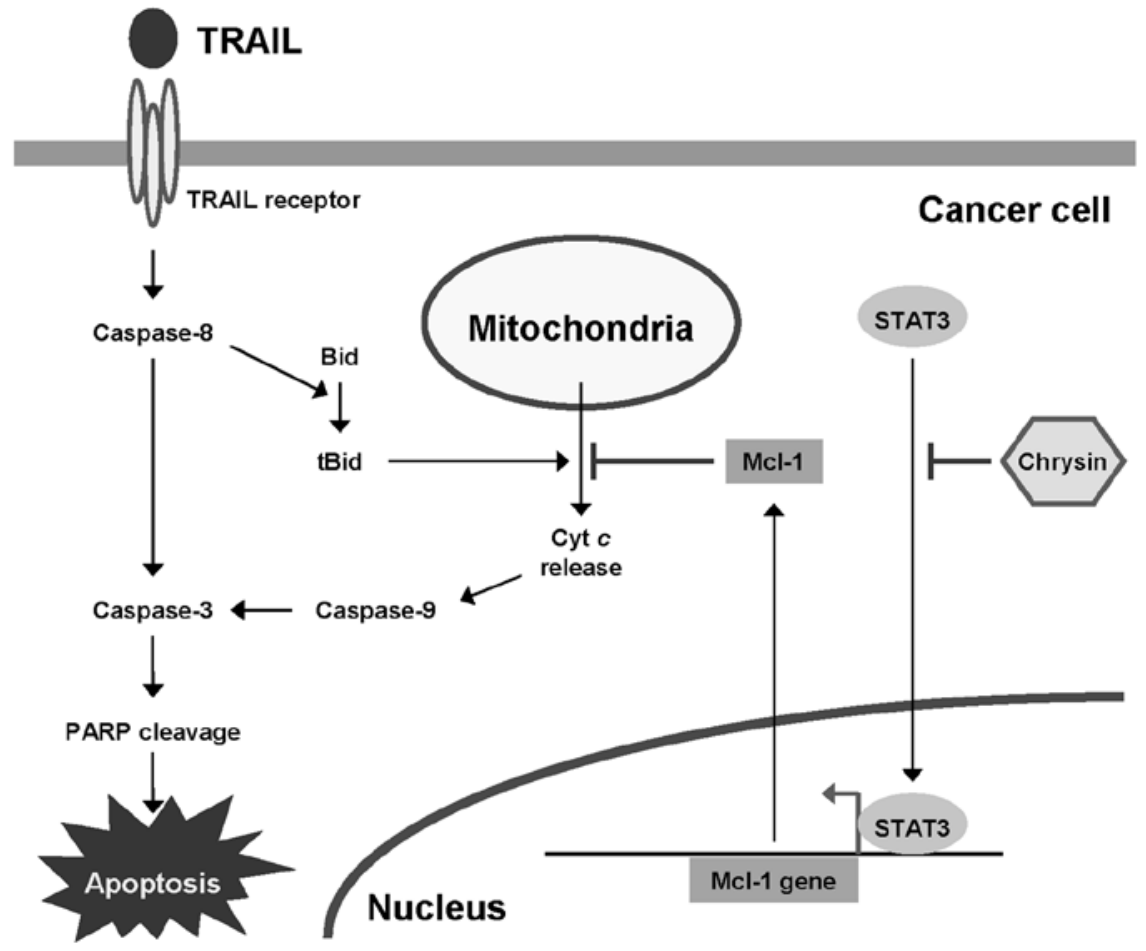

Figure 8. A model for mechanism of action of chrysin to overcome TRAIL resistance in cancer cells. Chrysin inhibits constitutive STAT3 activation in cancer cells leading to downregulation of Mcl-1 gene expression. When apoptotic signaling triggered by TRAIL receptor proceeds through caspase-8-mediated Bid cleavage, the decrease in Mcl-1 protein level facilitates tBid-induced cytochrome $c$ release from mitochondria, leading to caspase- 9 activation that synergizes with caspase-8 to activate caspase-3 and PARP cleavage. Thus the enhancement of TRAIL-induced apoptosis by chrysin is a result of cooperation between death receptor and mitochondrial pathways of apoptosis.

in expression regulation of STAT3 target genes coordinates the findings of Polier et al (37) and our results to depict the molecular details of the mechanism of Mcl-1 downregulation by chrysin via STAT3 inhibition.

Chrysin has been shown to inhibit Akt phosphorylation in cancer cells $(11,42)$. However, we did not observe inhibition of Akt phosphorylation by chrysin within the first $3 \mathrm{~h}$ after treatment (Fig. 6A), when the TRAIL-induced apoptosis had already progressed (Fig. 1E), and Mcl-1 level and STAT3 tyrosine phosphorylation were concomitantly decreased (Fig. 6B). Our results suggested that Akt inhibition was not the primary mechanism responsible for TRAIL sensitization effect of chrysin in our cellular models.

Although, inhibition of NF- $\mathrm{kB}$ activation was the mechanism of chrysin for enhancement of TNF $\alpha$-induced apoptosis in HCT116 colorectal cancer cells (15), chrysin did not inhibit TRAIL-induced NF- $\kappa$ B activation in A549 cells. Moreover, chrysin alone slightly increased NF- $\kappa B$ transcriptional activity (Fig. 2A), which was also observed in HeLa cells (data not shown). This phenomenon is consistent with a previous report showing that, in HeLa cells, chrysin induced DNA binding activity of p65 NF- $\kappa B$ which could be reversed by NAC pretreatment (43), indicating involvement of a glutathione depletion effect in the increased DNA binding activity of NF- $\kappa$ B by chrysin.

Our results clearly showed that NAC pretreatment did not abolish the TRAIL sensitization effect of chrysin, in contrast to curcumin, another glutathione depleting agent (Fig. 3), suggesting that the glutathione depletion effect did not contribute to TRAIL sensitization effect of chrysin. A recent report showed the ability of chrysin to activate AMP-activated protein kinase (AMPK), and this AMPK activation mediated enhancement of doxorubicin cytotoxicity in A549 cells (44). The report also demonstrated that AMPK activation led to inhibition of Akt phosphorylation and NAC pretreatment could reverse the AMPK activation. We suggest that the AMPK activation is unlikely to be involved in TRAIL sensitization effect of chrysin, because our results revealed that NAC pretreatment did not reverse TRAIL sensitization effect of chrysin (Fig. 3). We suggest that mechanisms of the biological effects of chrysin can be divided into glutathione depletion-dependent and -independent mechanisms.

In conclusion, as depicted in Fig. 8, we have demonstrated that chrysin can inhibit constitutive STAT3 activation, resulting in Mcl-1 downregulation, and this activity underlies the overcoming TRAIL resistance of cancer cells by chrysin. Our study suggests the potential of chrysin for use as a TRAIL sensitizer.

\section{Acknowledgements}

This study was supported by the Thailand Research Fund (TRG5380026 to K.L.), a Japanese-Thai Collaborative Scientific Research Fellowship (JSPS-NRCT; to K.L., S.A. and A.V.), and a research grant from the Chulabhorn Research Institute. We would like to thank Ms. Yue Zhou, Dr Orawin Prangsaengtong, Dr Rudee Surarit, Ms. Korakot Atjanasuppat, and Ms. Khajeelak Chiablaem for their assistance. 


\section{References}

1. Kruyt FA: TRAIL and cancer therapy. Cancer Lett 263: 14-25, 2008.

2. Wang S: The promise of cancer therapeutics targeting the TNF-related apoptosis-inducing ligand and TRAIL receptor pathway. Oncogene 27: 6207-6215, 2008

3. Hellwig CT and Rehm M: TRAIL signaling and synergy mechanisms used in TRAIL-based combination therapies. Mol Cancer Ther 11: 3-13, 2012.

4. Mahalingam D, Szegezdi E, Keane M, de Jong S and Samali A TRAIL receptor signalling and modulation: are we on the right TRAIL? Cancer Treat Rev 35: 280-288, 2009.

5. Ishibashi M and Ohtsuki T: Studies on search for bioactive natural products targeting TRAIL signaling leading to tumor cell apoptosis. Med Res Rev 28: 688-714, 2008.

6. Bankova V: Recent trends and important developments in propolis research. Evid Based Complement Alternat Med 2: 29-32, 2005

7. Szliszka E, Czuba ZP, Domino M, Mazur B, Zydowicz G and Krol W: Ethanolic extract of propolis (EEP) enhances the apoptosis-inducing potential of TRAIL in cancer cells. Molecules 14 738-754, 2009

8. Awale S, Shrestha SP, Tezuka Y, Ueda JY, Matsushige K and Kadota S: Neoflavonoids and related constituents from Nepalese propolis and their nitric oxide production inhibitory activity. J Nat Prod 68: 858-864, 2005.

9. Awale S, Li F, Onozuka H, Esumi H, Tezuka Y and Kadota S: Constituents of Brazilian red propolis and their preferential cytotoxic activity against human pancreatic PANC-1 cance cell line in nutrient-deprived condition. Bioorg Med Chem 16 181-189, 2008

10. Hernandez J, Goycoolea FM, Quintero J, et al: Sonoran propolis: chemical composition and antiproliferative activity on cancer cell lines. Planta Med 73: 1469-1474, 2007.

11. Woo KJ, Jeong YJ, Park JW and Kwon TK: Chrysin-induced apoptosis is mediated through caspase activation and Akt inactivation in U937 leukemia cells. Biochem Biophys Res Commun 325: 1215-1222, 2004

12. Weng MS, Ho YS and Lin JK: Chrysin induces G1 phase cell cycle arrest in C6 glioma cells through inducing p21Waf1/ Cip1 expression: involvement of p38 mitogen-activated protein kinase. Biochem Pharmacol 69: 1815-1827, 2005.

13. Kachadourian R, Leitner HM and Day BJ: Selected flavonoids potentiate the toxicity of cisplatin in human lung adenocar cinoma cells: a role for glutathione depletion. Int J Oncol 31 : 161-168, 2007.

14. Brechbuhl HM, Kachadourian R, Min E, Chan D and Day BJ: Chrysin enhances doxorubicin-induced cytotoxicity in human lung epithelial cancer cell lines: the role of glutathione. Toxicol Appl Pharmacol 258: 1-9, 2012.

15. Li X, Huang Q, Ong CN, Yang XF and Shen HM: Chrysin sensitizes tumor necrosis factor-alpha-induced apoptosis in human tumor cells via suppression of nuclear factor-kappaB. Cancer Lett 293: 109-116, 2010.

16. Li X, Wang JN, Huang JM, et al: Chrysin promotes tumor necrosis factor (TNF)-related apoptosis-inducing ligand (TRAIL) induced apoptosis in human cancer cell lines. Toxicol In Vitro 25: 630-635, 2011

17. Wagner H, Chari VM and Sonnenbichler J: 13C-NMR-spektren natürlich vorkommender flavonoide. Tetrahedron Lett 17: 17991802, 1976 (In German).

18. Gaydou EM and Bianchini JP: Études de composés flavoniques I Synthèses et propriétés (UV, RMN du 13C) de quelques flavones. Bull Soc Chim Fr II: 43-47, 1978.

19. Choo MK, Kawasaki N, Singhirunnusorn P, et al: Blockade of transforming growth factor-beta-activated kinase 1 activity enhances TRAIL-induced apoptosis through activation of a caspase cascade. Mol Cancer Ther 5: 2970-2976, 2006.

20. Lirdprapamongkol K, Kramb JP, Suthiphongchai T, et al: Vanillin suppresses metastatic potential of human cancer cells through PI3K inhibition and decreases angiogenesis in vivo. J Agric Food Chem 57: 3055-3063, 2009.

21. Lirdprapamongkol K, Sakurai H, Suzuki S, et al: Vanillin enhances TRAIL-induced apoptosis in cancer cells through inhibition of NF-kappaB activation. In Vivo 24: 501-506, 2010.

22. Yu C, Bruzek LM, Meng XW, et al: The role of Mcl-1 downregulation in the proapoptotic activity of the multikinase inhibitor BAY 43-9006. Oncogene 24: 6861-6869, 2005.
23. UngerRE,Krump-Konvalinkova V,Peters K and Kirkpatrick CJ: In vitro expression of the endothelial phenotype: comparative study of primary isolated cells and cell lines, including the novel cell line HPMEC-ST1.6R. Microvasc Res 64: 384-397, 2002.

24. Livak KJ and Schmittgen TD: Analysis of relative gene expression data using real-time quantitative PCR and the 2(-Delta Delta C(T)) method. Methods 25: 402-408, 2001.

25. Jung EM, Lim JH, Lee TJ, Park JW, Choi KS and Kwon TK: Curcumin sensitizes tumor necrosis factor-related apoptosisinducing ligand (TRAIL)-induced apoptosis through reactive oxygen species-mediated upregulation of death receptor 5 (DR5). Carcinogenesis 26: 1905-1913, 2005.

26. Jacquemin G, Shirley S and Micheau O: Combining naturally occurring polyphenols with TNF-related apoptosis-inducing ligand: a promising approach to kill resistant cancer cells? Cell Mol Life Sci 67: 3115-3130, 2010.

27. Bannerman DD, Tupper JC, Ricketts WA, Bennett CF, Winn RK and Harlan JM: A constitutive cytoprotective pathway protects endothelial cells from lipopolysaccharide-induced apoptosis J Biol Chem 276: 14924-14932, 2001.

28. Akgul C: Mcl-1 is a potential therapeutic target in multiple types of cancer. Cell Mol Life Sci 66: 1326-1336, 2009.

29. Aggarwal BB, Kunnumakkara AB, Harikumar KB, et al: Signal transducer and activator of transcription-3, inflammation, and cancer: how intimate is the relationship? Ann NY Acad Sci 1171: 59-76, 2009

30. Meng XW, Lee SH, Dai H, et al: Mcl-1 as a buffer for proapoptotic Bcl-2 family members during TRAIL-induced apoptosis: a mechanistic basis for sorafenib (Bay 43-9006)-induced TRAIL sensitization. J Biol Chem 282: 29831-29846, 2007.

31. Hsieh FC, Cheng G and Lin J: Evaluation of potential Stat3-regulated genes in human breast cancer. Biochem Biophys Res Commun 335: 292-299, 2005.

32. Nijhawan D, Fang M, Traer E, et al: Elimination of Mcl-1 is required for the initiation of apoptosis following ultraviolet irradiation. Genes Dev 17: 1475-1486, 2003.

33. Poukkula M, Kaunisto A, Hietakangas V, et al: Rapid turnover of c-FLIPshort is determined by its unique C-terminal tail. J Biol Chem 280: 27345-27355, 2005.

34. Dong Y, Yin S, Li J, Jiang C, Ye M and Hu H: Bufadienolide compounds sensitize human breast cancer cells to TRAIL-induced apoptosis via inhibition of STAT3/Mcl-1 pathway. Apoptosis 16: 394-403, 2011.

35. Huang S and Sinicrope FA: Sorafenib inhibits STAT3 activation to enhance TRAIL-mediated apoptosis in human pancreatic cancer cells. Mol Cancer Ther 9: 742-750, 2010.

36. Chen KF, Tai WT, Liu TH, et al: Sorafenib overcomes TRAIL resistance of hepatocellular carcinoma cells through the inhibition of STAT3. Clin Cancer Res 16: 5189-5199, 2010.

37. Polier G, Ding J, Konkimalla BV, et al: Wogonin and related natural flavones are inhibitors of CDK9 that induce apoptosis in cancer cells by transcriptional suppression of Mcl-1. Cell Death Dis 2: e182, 2011

38. Phan T, Yu XM, Kunnimalaiyaan $M$ and Chen $\mathrm{H}$ : Antiproliferative effect of chrysin on anaplastic thyroid cancer. J Surg Res 170: 84-88, 2011

39. Wang S and Fischer PM: Cyclin-dependent kinase 9: a key transcriptional regulator and potential drug target in oncology, virology and cardiology. Trends Pharmacol Sci 29: 302-313, 2008.

40. Giraud S, Hurlstone A, Avril S and Coqueret O: Implication of BRG1 and cdk9 in the STAT3-mediated activation of the p21waf1 gene. Oncogene 23: 7391-7398, 2004.

41. Hou T, Ray S and Brasier AR: The functional role of an interleukin 6-inducible CDK9.STAT3 complex in human gamma-fibrinogen gene expression. J Biol Chem 282: 37091-37102, 2007.

42. Fu B, Xue J, Li Z, Shi X, Jiang BH and Fang J: Chrysin inhibits expression of hypoxia-inducible factor-1alpha through reducing hypoxia-inducible factor-1alpha stability and inhibiting its protein synthesis. Mol Cancer Ther 6: 220-226, 2007.

43. Von Brandenstein MG, Ngum Abety A, Depping R, et al: A p38-p65 transcription complex induced by endothelin-1 mediates signal transduction in cancer cells. Biochim Biophys Acta 1783: 1613-1622, 2008

44. Shao JJ, Zhang AP, Qin W, Zheng L, Zhu YF and Chen X: AMP-activated protein kinase (AMPK) activation is involved in chrysin-induced growth inhibition and apoptosis in cultured A549 lung cancer cells. Biochem Biophys Res Commun 423: $448-453,2012$ 